\title{
Produtividade de beterraba em função de doses de sulfato de amônio em cobertura
}

\author{
Paulo E. Trani' ${ }^{1}$; Heitor Cantarella²; Sebastião W. Tivelli' \\ ${ }^{1}$ Instituto Agronômico, Centro de Horticultura, C. Postal 28, 13001-970 Campinas-SP; ${ }^{2}$ Instituto Agronômico, Centro de Solos, C. Postal \\ 28, 13001-970 Campinas-SP; E-mail: petrani@iac.sp.gov.br;
}

\section{RESUMO}

No estado de São Paulo foram conduzidos, em duas localidades, três experimentos de campo com a beterraba cultivar Top Tall Early Wonder com o objetivo de avaliar a produção total de raízes e parte aérea sob diferentes doses de $\mathrm{N}$ aplicadas em cobertura. $\mathrm{O}$ primeiro experimento foi realizado em Monte Alegre do Sul (SP) em um Argissolo Vermelho Amarelo distrófico e os dois últimos foram instalados em Campinas (SP) em um Latossolo Vermelho Amarelo distrófico. Os três experimentos foram conduzidos no delineamento de blocos casualizados com seis repetições. As doses de nitrogênio foram parceladas em duas aplicações, na forma de sulfato de amônio, e variaram de zero a $200 \mathrm{~kg} \mathrm{ha}^{-1}$. No primeiro experimento a produtividade máxima de raízes de beterraba foi atingida com $92 \mathrm{~kg}_{\text {de N ha}}{ }^{-1}$ em cobertura, no segundo com $179 \mathrm{~kg}$ de $\mathrm{N} \mathrm{ha}^{-1}$, e no último experimento com $151 \mathrm{~kg} \mathrm{~N} \mathrm{ha}^{-1}$. A produtividade da parte aérea em todos os experimentos foi linear e positiva. As maiores produtividades de beterraba para a comercialização em maços (raízes e folhas) foram obtidas com a maior dose de $\mathrm{N}$ em cobertura, ou seja, $200 \mathrm{~kg} \mathrm{~N} \mathrm{ha}^{-1}$. Foi encontrada uma relação linear e positiva entre o teor de $\mathrm{N}$ das raízes e parte aérea com as doses de $\mathrm{N}$ aplicadas em cobertura.

Palavras-chave: Beta vulgaris L., adubação nitrogenada em cobertura, teor de $\mathrm{N}$.

\begin{abstract}
Table beet yield depending on rates of ammonium sulphate applied as side dressing

Three field experiments were carried out in two locations in São Paulo State, Brazil, to evaluate the total root and above ground yields of table beets under different nitrogen rates. One experiment was carried out in Monte Alegre do Sul on a Typic Kandaudult and the others in Campinas on a Typic Hapludox. The experimental design was of complete randomized blocks with six replications. Nitrogen rates varying from zero to $200 \mathrm{~kg} \mathrm{ha}^{-1}$ were split in two applications using ammonium sulphate. In the first field trial the maximum root yield of table beets was reached with $92 \mathrm{~kg}$ of $\mathrm{N} \mathrm{ha}^{-1}$, in the second with $179 \mathrm{~kg}$ of N.ha-1, and in the third with $151 \mathrm{~kg}$ of N.ha- ${ }^{-1}$. The yield response of above ground to $\mathrm{N}$ application in all experiments was linear and positive. The highest yield of table beets for sale on bunches (roots and leaves) was obtained when the maximum rate of $\mathrm{N}$ was applied $\left(200 \mathrm{~kg} \mathrm{~N} \mathrm{ha}^{-1}\right)$. In all three experiments a linear and positive relationship was found between rates of $\mathrm{N}$ applied and $\mathrm{N}$ content on roots and above ground.
\end{abstract}

Keywords: Beta vulgaris L., side dressing nitrogen rates, $\mathrm{N}$ content in table beets.

\section{(Recebido para publicação em 10 de maio de 2004 e aceito em 9 de maio de 2005)}

\begin{abstract}
$\mathrm{A}$ beterraba é uma raiz tuberosa, originária da Europa, pertencente à família Quenopodiácea. Das 100.500 propriedades produtoras de beterraba existentes no Brasil, $42 \%$ estão na Região Sudeste e $35 \%$ na Região Sul. No estado de São Paulo são cultivados 5.000 hectares em média por ano (CAMARGO FILHO; MAZZEI, 2002).
\end{abstract}

A área cultivada de beterraba no estado de São Paulo praticamente dobrou desde 1994. No perído de janeiro de 1998 a outubro de $2004,91 \%$ da beterraba comercializada pela Ceagesp-SP foi na forma de raízes (caixa $\mathrm{K}$ com 20 $\mathrm{kg}$ ) e os restantes $9 \%$ foram comercializados com folha (engradados com 20 $\mathrm{kg}$ ). Neste período, o preço médio mensal da caixa $K$ foi de $R \$ 8,47$ enquanto do engradado foi de $\mathrm{R} \$ 7,88$. Em mé- dia, a Ceagesp-SP comercializou 25.112 toneladas de beterraba por ano durante o período, o que representa apenas $21,84 \%$ da beterraba produzida no estado de São Paulo ${ }^{1}$.

Em um diagnóstico da produção de hortaliças no estado de São Paulo constatou-se que o cultivo de beterraba estava entre as 15 principais hortaliças em área plantada em 1994 (TRANI et al., 1997a). Estes autores constataram a necessidade de pesquisas para a adubação na cultura da beterraba.

Laske (1962) encontrou grande diferença na recomendação de adubação de plantio e cobertura para a beterraba de mesa em revisões sobre essa cultura. $\mathrm{O}$ autor verificou que nos Estados Unidos as recomendações mudam de estado para estado, desde ausência de co- bertura nitrogenada até $225 \mathrm{~kg} \mathrm{ha}^{-1}$ de nitrato de sódio $\left(\mathrm{NaNO}_{3}\right)$. $\mathrm{Na}$ Inglaterra, as adubações de cobertura nitrogenada eram feitas somente se necessário enquanto na África do Sul se utilizava 100 a $150 \mathrm{~kg} \mathrm{ha}^{-1}$ de adubo nitrogenado. Finalmente, o autor encontrou que na Alemanha, a beterraba de mesa recebe de 300 a $400 \mathrm{~kg} \mathrm{ha}^{-1}$ de nitrocálcio em cobertura.

Em sete experimentos onde a dosagem de nitrato de amônio foi avaliada em áreas comerciais do estado de Nova Iorque para a cultura de beterraba de mesa, Shannon et al. (1967) encontram um aumento significativo na produção total de raízes e na qualidade de raízes com o aumento da dosagem de nitrogênio até $168 \mathrm{~kg} \mathrm{ha}^{-1}$. O teor de $\mathrm{N}$ encontrado nas folhas e nas raízes aumentou

\footnotetext{
${ }^{1}$ Dados estatísticos obtidos na Seção de Economia e Desenvolvimento da CEAGESP (n.p.)
} 
com o aumento das dosagens de N. Segundo estes autores, os produtores obtiveram o melhor retorno econômico com a adubação de cobertura de $84 \mathrm{~kg} \mathrm{ha}^{-1}$ de $\mathrm{N}$ em beterraba.

Considerando a dosagem de $\mathrm{N}$ aplicada no plantio e em cobertura, Hemphill et al. (1982) e Mack (1989) encontram resultados similares para as maiores dosagens estudadas, respectivamente, $280 \mathrm{~kg} \mathrm{ha}^{-1}$ e $224 \mathrm{~kg} \mathrm{ha}^{-1}$ de $\mathrm{N}$. Mack (1989) constatou que a concentração de nitrogênio nas folhas aumentava quando a dosagem de $\mathrm{N}$ no solo era elevada.

A resposta a $\mathrm{N}$ depende também do tipo de solo. Pereira et al. (1995), ao estudarem doses de 20 a $320 \mathrm{~kg}$ de $\mathrm{N}$ ha $^{-1}$, não obtiveram resposta à adubação de cobertura de beterraba com nitrocálcio. Estes autores avaliaram a beterraba cv. Top Tall Early Wonder em Viçosa (MG) em um solo (cuja classificação não foi mencionada) com alto teor de nitrogênio.

Haag e Minami (1987) avaliaram o crescimento da beterraba através da produção de matéria seca em um solo de ótima fertilidade natural. Os autores verificaram aumento de matéria fresca e seca da parte aérea e das raízes até o final do ciclo da cultura por volta de 80 dias. Isto indica que a absorção de nutrientes, incluindo o nitrogênio, ocorre até próximo a colheita. Ferreira e Tivelli (1990) indicavam o uso de $80 \mathrm{~kg}$ de $\mathrm{N}$ ha $^{-1}$ na adubação da beterraba em cobertura. Segundo os autores, este montante deve ser parcelado em duas aplicações. A primeira aplicação $\left(40 \mathrm{~kg}\right.$ de $\left.\mathrm{N} \mathrm{ha}^{-1}\right)$ é feita por ocasião do desbaste, na cultura de semeadura direta, ou 15-20 dias após o transplante das mudas. Independentemente do sistema de plantio, a segunda aplicação é feita 20 dias após a primeira.

A recomendação oficial para o estado de São Paulo preconiza a aplicação de 60 a $120 \mathrm{~kg} \mathrm{ha}^{-1}$ de $\mathrm{N}$ em cobertura para a cultura da beterraba (TRANI et al., 1997b). Este total deve ser parcelado em três aplicações, aos 15,30 e 50 dias após a germinação.

Trani et al. (1993) ao revisarem os efeitos do nitrogênio na adubação de beterraba verificaram serem vários os fatores que interferem na sua eficácia.
Por exemplo, a resposta à aplicação de nitrogênio em beterraba depende do tipo de solo, da temperatura, da época e maneira de adubação, e da fonte de nitrogênio. Segundo os autores, a interação destes fatores esclarece as diferenças significativas que há nas doses de nitrogênio recomendadas em literatura.

Diante da variabilidade de resultados observados na literatura ainda persistem dúvidas sobre as doses mais adequadas de N para essa cultura no estado de São Paulo tanto para a produção de raízes quanto da parte aérea. Assim, o objetivo deste trabalho foi avaliar a produção total de raízes e parte aérea de beterraba, e o teor de nitrogênio na parte aérea e nas raízes em função da dosagem de $\mathrm{N}$ aplicada em cobertura.

\section{Material e Métodos}

Três experimentos de campo foram conduzidos para avaliação de dosagens de nitrogênio $(\mathrm{N})$ em cobertura na cultura da beterraba cv. "Top Tall Early Wonder". O primeiro experimento foi realizado em 1990 (ano 1) na Estação Experimental de Monte Alegre do Sul do IAC. Os demais experimentos foram realizados na Fazenda Santa Elisa do IAC em Campinas em 1991 e 1992, respectivamente ano 2 e ano 3 .

No primeiro experimento, o solo foi um Argissolo Vermelho Amarelo distrófico de textura média, com as seguintes características químicas na camada arável $(0-20 \mathrm{~cm}): \mathrm{pH}$ em $\mathrm{CaCl}_{2}=$ 5,5; M.O. $=33 \mathrm{~g} \mathrm{dm}^{-3} ; \mathrm{P}=35 \mathrm{mg} \mathrm{dm}^{-3} ; \mathrm{K}$ $=5,5 \mathrm{mmol}_{\mathrm{c}} \mathrm{dm}^{-3} ; \mathrm{Ca}=32 \mathrm{mmol}_{\mathrm{c}} \mathrm{dm}^{-3}$; $\mathrm{Mg}=10 \mathrm{mmol} \mathrm{dm}{ }^{-3} ; \mathrm{H}+\mathrm{Al}=28 \mathrm{mmol}$ $\mathrm{dm}^{-3} ; \mathrm{CTC}=76 \mathrm{mmol} \mathrm{dm}^{-3} \mathrm{e} \mathrm{V}=63 \%$. A calagem foi feita com 1,4 $\mathrm{t} \mathrm{ha}^{-1} \mathrm{de}$ calcário dolomítico, visando atingir $80 \%$ de saturação por bases (CATANI; GALLO, 1955). O segundo e terceiro experimentos foram realizados em um Latossolo Vermelho Amarelo distrófico de textura argilosa, com as seguintes características químicas na camada arável (0-20 cm): $\mathrm{pH}$ em $\mathrm{CaCl}_{2}=5,3 ;$ M.O. $=22 \mathrm{~g} \mathrm{dm}^{-3} ; \mathrm{P}=24 \mathrm{mg} \mathrm{dm}^{-3} ; \mathrm{K}=3,6$ mmol dm ${ }^{-3} ; \mathrm{Ca}=24 \mathrm{mmol} \mathrm{dm}^{-3} ; \mathrm{Mg}=$ $13 \mathrm{mmol}_{\mathrm{c}} \mathrm{dm}^{-3} ; \mathrm{H}+\mathrm{Al}=38 \mathrm{mmol} \mathrm{dm}^{-3}$, $\mathrm{CTC}=78 \mathrm{mmol}_{\mathrm{c}} \mathrm{dm}^{-3} \mathrm{e} \mathrm{V}=51 \%$. A necessidade de calagem nesta área foi de 2,4 t ha-1 de calcário dolomítico, visando atingir $80 \%$ de saturação por bases (CATANI; GALLO, 1955).
Em todos os locais as quantidades aplicadas de fósforo e potássio foram baseadas em Fornasier e Lisbão (1985). O fósforo foi aplicado na forma de superfosfato simples e o potássio na forma de cloreto de potássio nas doses de $1500 \mathrm{~kg} \mathrm{ha}^{-1}$ e $100 \mathrm{~kg} \mathrm{ha}^{-1}$, respectivamente. A dosagem de superfosfato simples forneceu $150 \mathrm{~kg} \mathrm{ha}^{-1}$ de enxofre, considerados suficiente para atender as necessidades desse nutriente pela beterraba. Foi ainda aplicado no sulco de plantio $3 \mathrm{~kg} \mathrm{ha}^{-1}$ de boro na forma de bórax.

Todos os experimentos foram conduzidos em canteiros com 1,2 metro de largura e a semeadura realizada em linhas longitudinais num total de 4 linhas por canteiro. $\mathrm{O}$ delineamento estatístico foi o de blocos ao acaso com seis repetições. Cada parcela tinha 2,5 metros de comprimento, perfazendo um total de 3,0 $\mathrm{m}^{2}$ de área total e 1,5 $\mathrm{m}^{2}$ de área útil, sendo as duas linhas centrais utilizadas para as avaliações.

No experimento 1 (ano 1) em Monte Alegre do Sul (SP) a beterraba foi semeada em 08/06/1990 e colhida em 12/09/1990 (ciclo 97 dias). O espaçamento entre linhas foi de $20 \mathrm{~cm}$ e o espaçamento entre plantas após o desbaste foi de $7 \mathrm{~cm}$. Neste experimento foram avaliadas quatro doses de $\mathrm{N}$ em cobertura ( $0 ; 40 ; 80$; e $120 \mathrm{~kg}$ de $\mathrm{N}$ $\left.\mathrm{ha}^{-1}\right)$. A fonte de nitrogênio foi o sulfato de amônio. As dosagens de $\mathrm{N}$ foram parceladas em duas aplicações, sendo a primeira logo após o desbaste (28 dias após a germinação) e a segunda 21 dias após a primeira. Avaliou-se o peso de matéria fresca de raízes e da parte aérea, e o peso de matéria seca da parte aérea. Os resultados para peso matéria fresca de raízes e da parte aérea foram transformados para produção/ha (produtividade) e expressos em $\mathrm{t} \mathrm{ha}^{-1}$. Para a análise do peso de matéria seca da parte aérea foram colhidas 15 plantas ao acaso por parcela. Considera-se folha de beterraba a soma do pecíolo mais o limbo foliar, o que coincide com a parte aérea da planta.

No experimento 2 (ano 2) realizado em Campinas (SP), a beterraba foi semeada em 20/06/1991 e colhida em 23/09/1991 (ciclo 96 dias). A germinação ocorreu 6 dias após a semeadura e o 


\section{RAIZES (1a)}
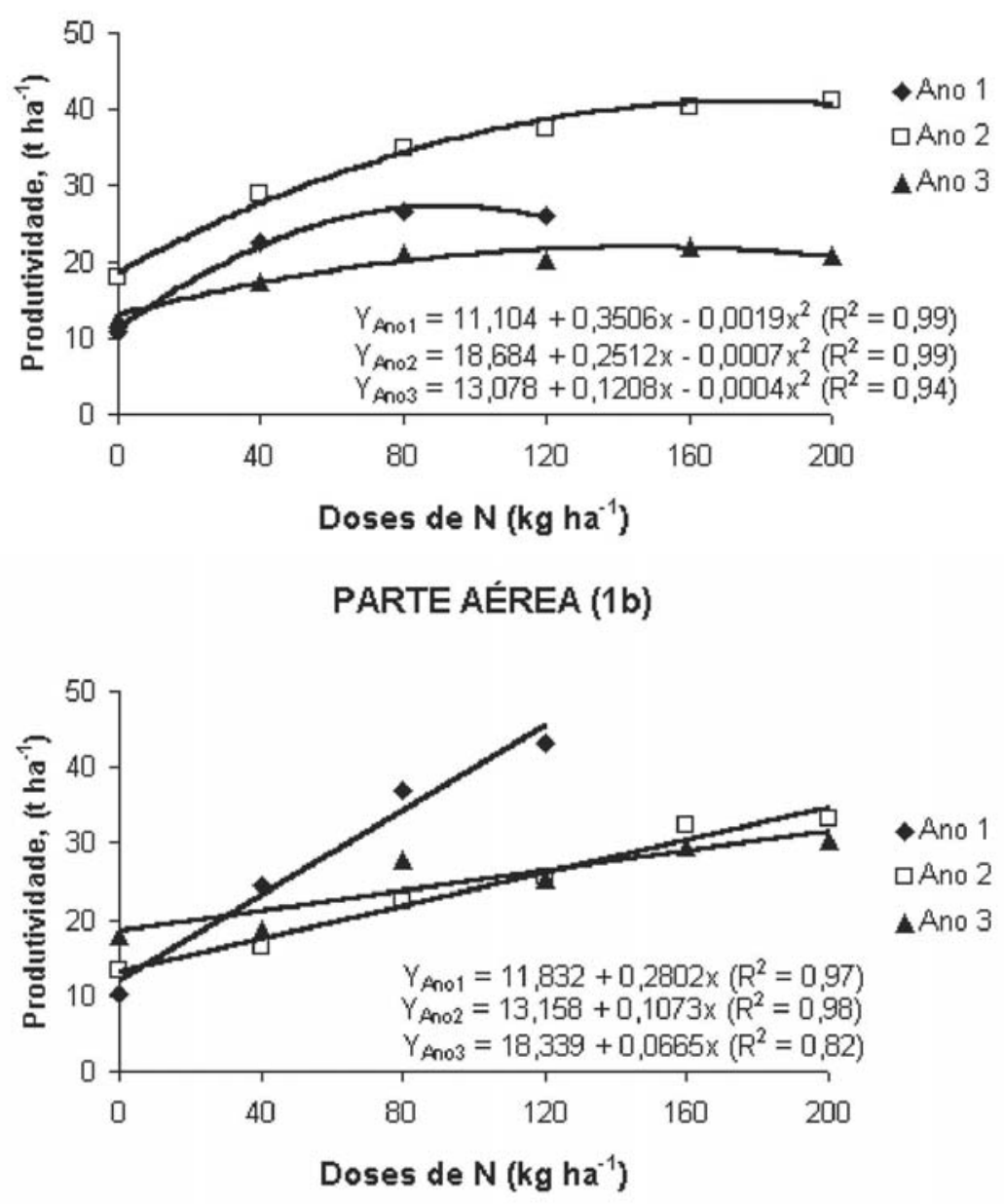

Figura 1. Produção de raízes (a) e parte aérea (b) de beterraba em função de doses de $\mathrm{N}$ em cobertura nos experimentos: anos 1) Monte Alegre do Sul (SP), e nos Anos 2) e 3) Campinas (SP). Campinas, IAC, 1990 a 1992.

desbaste 27 dias após a germinação. $\mathrm{O}$ espaçamento entre linhas foi de $25 \mathrm{~cm}$ e o espaçamento entre plantas após o desbaste foi de $12,5 \mathrm{~cm}$. Foram avaliadas seis doses de $\mathrm{N}$ em cobertura $(0 ; 40$; $80 ; 120 ; 160$ e $200 \mathrm{~kg}$ de N.ha ${ }^{-1}$ ) neste experimento, sendo a fonte de $\mathrm{N}$ o sulfato de amônio. Tais doses de $\mathrm{N}$ em quantidades maiores do que aquelas do ano 1 , foram utilizadas considerando-se que o solo de Campinas (SP) apresenta teor menor de M.O. $\left(22 \mathrm{~g} \mathrm{dm}^{-3}\right)$ do que o solo de Monte Alegre do Sul (SP), e a resposta a produtividade da parte aérea terem sido positivas e linear no ano 1 . As dosagens de $\mathrm{N}$ foram parceladas em duas aplicações, com a primeira logo após o desbaste (31 dias após a germinação) e a segunda 21 dias após a primeira. Na colheita avaliou-se o peso de matéria fres- ca de raízes e da parte aérea.

A análise econômica no experimento 2 (ano 2) foi calculada com base no preço médio da caixa $\mathrm{K}$ e do engradado de beterraba no período de janeiro de 1998 a outubro de 2004. A inclinação da curva da produtividade de raízes e da parte aérea na equação do ano 2 , fornece o acréscimo na produtividade para cada quilograma de $\mathrm{N}$ aplicado à cultura nesse experimento. Os aumentos de produtividade de raízes e da parte aérea foram divididos pelo peso da caixa $\mathrm{K}$ e do engradado de beterraba, e esse valor multiplicado pelo preço médio respectivo. Esse cálculo mostra o aumento da receita bruta do produtor para cada quilograma de $\mathrm{N}$ aplicado, o qual foi comparado com o preço do quilograma de $\mathrm{N}$ em Campinas.
No experimento 3 (ano 3), a beterraba foi semeada em 14/07/1992 e colhida em 14/10/1992 (ciclo 89 dias). A germinação ocorreu 6 dias após a semeadura e o desbaste 24 dias após a germinação. $\mathrm{O}$ espaçamento adotado no ano 3 foi o mesmo do ano anterior. As doses de $\mathrm{N}$ no ano 3 foram as mesmas do ano 2 em razão da máxima produtividade de raízes ocorrer em níveis próximos a $200 \mathrm{~kg}$ de $\mathrm{N} \mathrm{ha}^{-1}$. As dosagens de $\mathrm{N}$ foram parceladas em duas aplicações de cobertura, sendo a primeira no mesmo dia do desbaste (24 dias após a germinação) e a segunda 20 dias após a primeira. Neste experimento foram avaliados o peso de matéria fresca de raízes e da parte aérea, o peso de matéria seca de raízes e da parte aérea, e o teor de $\mathrm{N}$ nas raízes e na parte aérea. Os resultados para peso de matéria fresca de raízes e da parte aérea foram transformados para produção/ha (produtividade) e expressos em $t$ ha $^{-1}$.

Para a avaliação dos teores de $\mathrm{N}$ nas raízes e na parte aérea foram coletadas ao acaso 15 plantas por parcelas após a pesagem para a coleta dos dados de peso fresco. As amostras foram secadas em estufa com circulação de ar forçada a $65^{\circ} \mathrm{C}$ até peso constante e analisadas para $\mathrm{N}$ de acordo com os procedimentos descritos por Bataglia et al. (1983). A qualidade das raízes foi avaliada nos anos 1, 2 e 3 através da média do maior diâmetro transversal das raízes de beterraba produzidas na área útil de cada parcela.

Os resultados foram submetidos à análise de variância com o programa estatístico Sanest. A análise de variância para o efeito da regressão polinomial mostrou-se significativa pelo teste $\mathrm{F}$ para as características avaliadas, exceto para a qualidade das raízes. A curva de resposta de cada característica foi obtida pela regressão polinomial para os níveis de doses.

\section{RESULTADOS E DISCUSSÃO}

Os resultados do experimento 1 (ano 1) indicaram que a produtividade máxima de raízes de beterraba foi atingida com $92 \mathrm{~kg}$ de $\mathrm{N} \mathrm{ha}^{-1}$ em cobertura (Figura 1a). A dose de $\mathrm{N}$ em cobertura que proporcionou a produtividade máxima 
de raízes nesse experimento encontrase acima das recomendadas por Ferreira e Tivelli (1990), com $80 \mathrm{~kg} \mathrm{~N} \mathrm{ha}^{-1}$, e entre as preconizadas Trani et al. (1997b) que foram de 60 a $120 \mathrm{~kg} \mathrm{~N} \mathrm{ha}^{-1}$. É provável que o Argissolo Vermelho Amarelo apresentando teor de M.O. de 33 g.dm ${ }^{-3}$ supriu boa parte do nitrogênio requerido pela beterraba por meio da mineralização da matéria orgânica. Por um outro lado, a produtividade da parte aérea da beterraba apresentou-se diretamente proporcional a dose de $\mathrm{N}$ utilizada em cobertura (Figura 1b).

No experimento 2 (ano 2), as doses de $\mathrm{N}$ em cobertura foram ampliadas para até $200 \mathrm{~kg}$ de $\mathrm{N}$ por hectare a fim de avaliar os resultados de altas doses de $\mathrm{N}$ em cobertura devido a importância do volume (produção) de folhas na cultura para aqueles produtores que comercializam a beterraba em engradados. Além disso, nos trabalhos de Shannon et al. (1967), Hemphill et al. (1982), e Mack (1989) doses altas de N em cobertura contribuíram para a melhora da qualidade das raízes e para o aumento da produtividade.

Os resultados do experimento 2 (ano 2) apresentaram tendência semelhante aos resultados do ano 1 . As respostas às doses de $\mathrm{N}$ foram quadrática para a produtividade total de raízes (Figuras 1a) e lineares e positivas para a produtividade da parte aérea (Figura 1b). Observouse que a máxima produtividade total de raízes foi alcançada com $179 \mathrm{~kg} \mathrm{~N} \mathrm{ha}^{-1}$. Este resultado confirma os trabalhos de Shannon et al. (1967), Hemphill et al. (1982), e Mack (1989) quanto ao aumento na produtividade verificada com doses mais altas de $\mathrm{N}$ em cobertura. No ano 2 encontrou-se também uma relação direta e positiva entre a produtividade da parte aérea e a dose de $\mathrm{N}$ em cobertura.

A análise economica do experimento do ano 2 é amplamente favorável à elevação da dose de $\mathrm{N}$ em cobertura. Neste experimento, cada quilograma de $\mathrm{N}$ aplicado em cobertura proporcionou um acréscimo na produtividade de raízes e parte aérea de beterraba de 251 e 107 $\mathrm{kg} \mathrm{ha}^{-1}$, respectivamente. $\mathrm{O}$ incremento na produção representa 12,5 caixas $\mathrm{K}$ ou cerca de 17,9 engradados a mais de beterraba para cada quilograma de $\mathrm{N}$

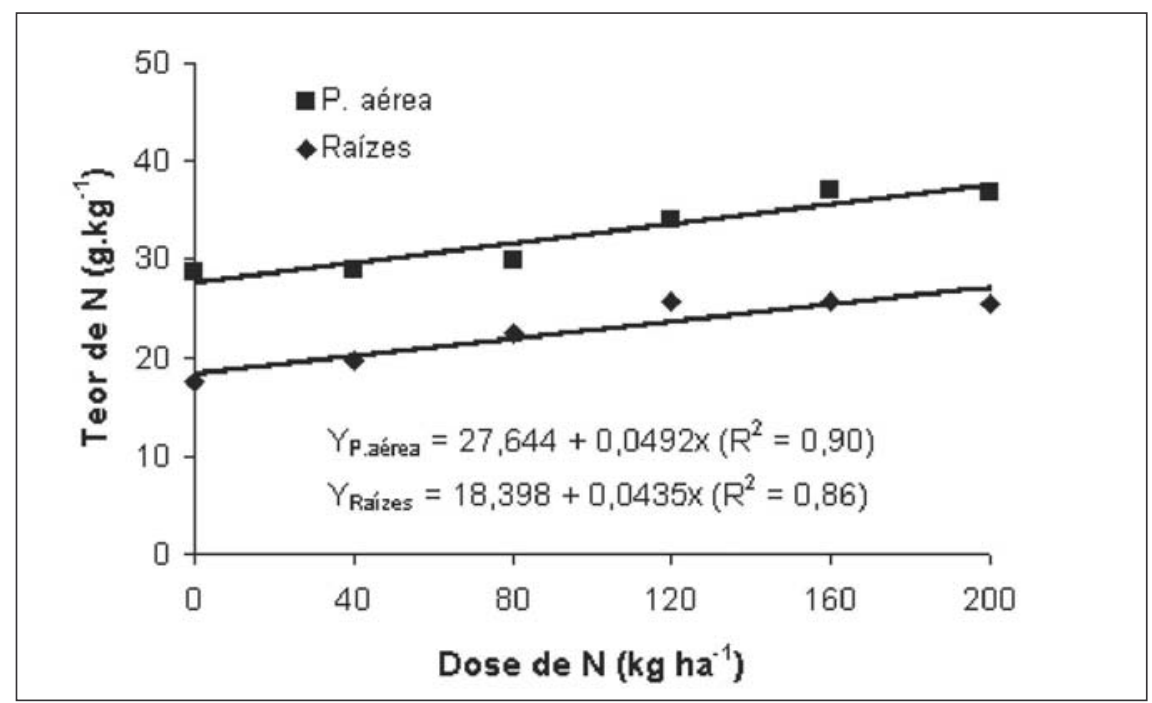

Figura 2. Teor de $\mathrm{N}$ na planta de beterraba em função de doses de $\mathrm{N}$ em cobertura no ano 3) Campinas (SP). Campinas, IAC, 1992.

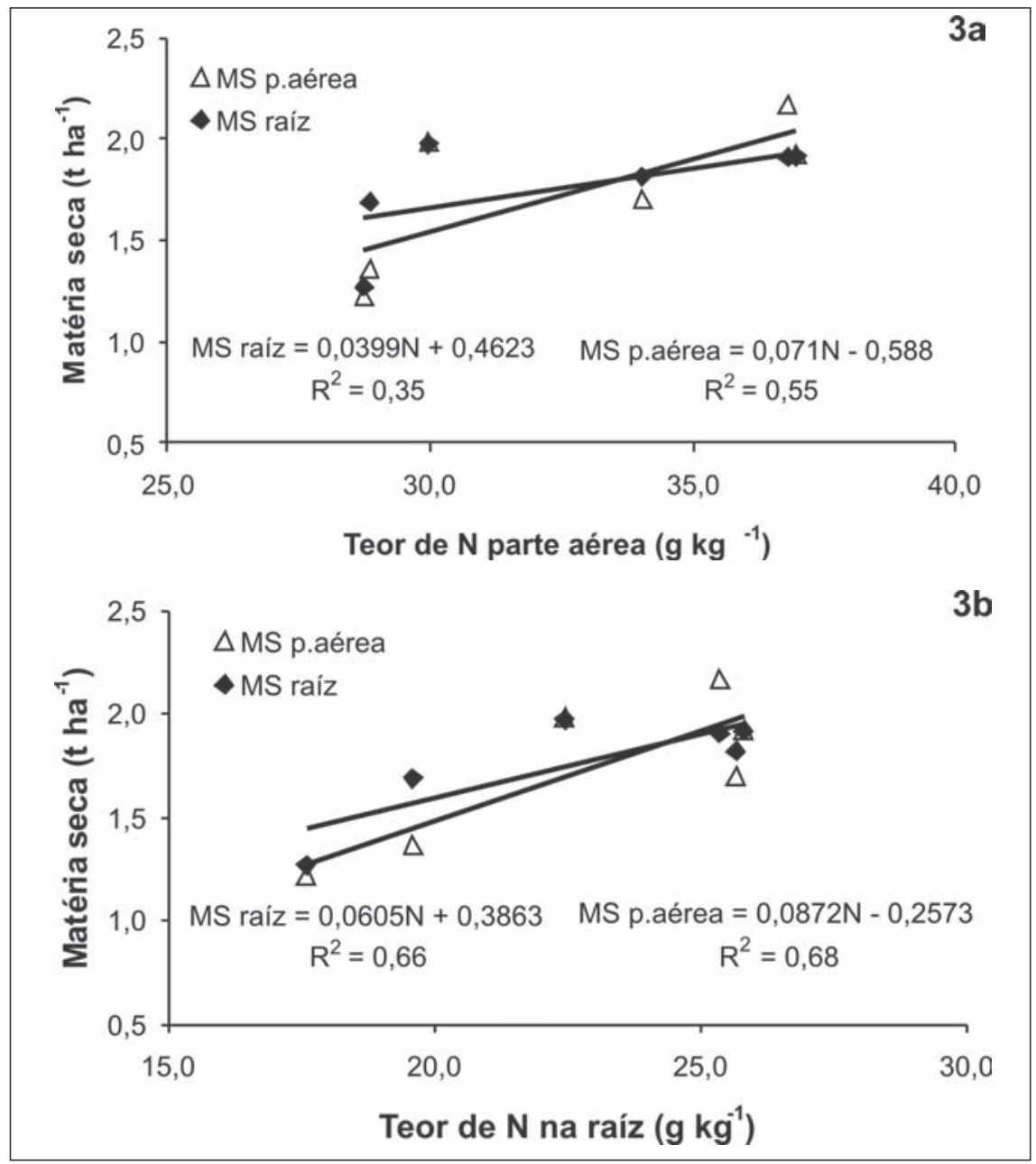

Figura 3. Produção de matéria seca da parte aérea e de raízes de beterraba em função do teor de N no ano 3) Campinas (SP). Campinas, IAC, 1992.

dependendo da modalidade de comercialização do produtor. Considerando o preço médio da caixa $\mathrm{K}$ e do engradado do produto no quinqüênio 1998-2002, o produtor estaria gerando $\mathrm{R} \$ 105,88$ se comercializasse a produ- 
ção em caixas K ou $\mathrm{R} \$ 141,05$ se o fizesse em engradados para cada quilograma de $\mathrm{N}$ aplicado em cobertura. $\mathrm{O}$ quilograma de $\mathrm{N}$ em Campinas custa ao produtor $\mathrm{R} \$ 3,32$ quando adquirido na forma de sulfato de amônio ou equivalente, como o nitrato de amônio.

No terceiro experimento foram mantidas as mesmas doses de $\mathrm{N}$ em cobertura apesar da favorável resposta a produtividade da parte aérea. A decisão de não aumentar a dose de $\mathrm{N}$ em cobertura na cultura da beterrava em Campinas no ano 3 deve-se aos resultados de Shannon et al. (1967). Estes autores constataram que ao aumentar a dose de $\mathrm{N}$ em cobertura o teor de solídos solúveis e o teor da pigmentação avermelhada (betalaína) diminuem. A diminuição no teor de betalaína pode representar um deságio no preço da beterraba para o produtor.

A produtividade total de raízes no experimento do ano 3 apresentou uma resposta quadrática semelhante a que havia ocorrido nos experimentos anteriores (Figura 1a), sendo a máxima produtividade total de raízes alcançada com $151 \mathrm{~kg} \mathrm{~N} \mathrm{ha}^{-1}$. Assim como havia ocorrido nos experimentos anteriores a qualidade das raízes não foi influenciada pela dose de $\mathrm{N} \mathrm{ha}^{-1}$. A produtividade da parte aérea por sua vez foi também linear e positiva no ano 3 semelhantemente ao que ocorreu nos anos 1 e 2 (Figura 1b).

Verificou-se existir relação linear e positiva entre os teores de $\mathrm{N}$ das raízes e parte aérea com as doses de $\mathrm{N}$ aplicada em cobertura (Figura 2). A análise do teor de $\mathrm{N}$ nas raízes e parte aérea confirma os resultados obtidos por Shannon et al. (1967) e Mack (1989).

$\mathrm{O}$ rendimento de matéria seca (MS) da parte aérea e das raízes da beterraba mostrou relação linear com os teores de $\mathrm{N}$ na planta (Figura 3a e 3b). Os coeficientes de regressão das Figuras $3 a$ e $3 b$ sugerem que o teor de $\mathrm{N}$ das raízes em comparação com o $\mathrm{N}$ da parte aérea, explica melhor as variações de produção de matéria seca tanto das raízes quanto da parte aérea da beterraba.
Os maiores rendimentos observados conforme doses crescentes de $\mathrm{N}$ podem ser decorrentes do maior diâmetro das raízes. Porém, os altos valores do coeficiente de variação não tornaram conveniente a apresentação destes resultados.

Para a definição da dose de $\mathrm{N}$ em cobertura para a cultura da beterraba deve-se considerar se a produção será vendida em caixas $\mathrm{K}$ (apenas raízes) ou engradado (raízes e folhas). Para a comercialização das raízes em caixa $\mathrm{K}$, a dose de $\mathrm{N}$ em cobertura maior do que a recomendada por Trani et al. (1997b) para o estado de São Paulo pode ou não aumentar a produtividade da cultura. A dose ótima de $\mathrm{N}$ parece depender das condições edafoclimáticas do local de cultivo. Isto explicaria as informações contraditórias presentes na literatura. Por outro lado, os dados do presente estudo indicam que as doses de $\mathrm{N}$ atualmente recomendadas no estado de São Paulo (TRANI et al., 1997b) podem ser aumentadas quando a comercialização dessa hortaliça for feita em maços.

As maiores produtividades de raízes e parte áerea de beterraba foram obtidas com aplicação da maior dose de $\mathrm{N}$ em cobertura (200 kg N ha-1). Para os anos 1, 2 e 3, consideram-se como satisfatórias as doses de nitrogênio de 92,179 e $151 \mathrm{~kg} \mathrm{ha}^{-1}$, para as melhores produtividades de raízes de beterraba. Esses valores ratificam a importância da realização de experimentos de adubação nitrogenada em diferentes tipos de solo.

\section{AGRADECIMENTOS}

Agradecemos ao pesquisador Dr. Francisco Antonio Passos pela orientação com o programa estatístico Sanest.

\section{LITERATURA CITADA}

BATAGLIA, O.C. ;FURLANI, A.M.C.; TEIXEIRA, J.P.F.; FURLANI, P.R.; GALLO, J.R. Métodos de análise química de plantas. Campinas, Instituto Agronômico, 1983. 48 p (Boletim Técnico, 78)

CAMARGO FILHO, W.P.; MAZZEI, A.R. Mercado de beterraba em São Paulo. Informações Econômicas, São Paulo, v.32, n.4, p.54-56, 2002.
CATANI, R.A.; GALLO, J.R. Avaliação da exigência em calcário dos solos do estado de São Paulo, mediante correlação entre o $\mathrm{pH}$ e a porcentagem de saturação em bases. Revista de Agricultura, Piracicaba, v.30, p.49-60, 1955.

FERREIRA, M.D.; TIVELLI, S.W. Cultura da beterraba: condições gerais. 3. ed. Guaxupé: Indústrias Gráficas Pirassununga Ltda., 1990. p.14. FORNASIER, J.B.; LISBÃO, R.S. Beterraba, cenoura, nabo e rabanete. In: RAIJ, B. van.; SILVA, N.M.; BATAGLIA, O.C.; QUAGGIO, J.A.; HIROCE, R.; CANTARELLA, H.; BELLINAZZI JÚNIOR, R.; DECHEN, A.D.; TRANI, P.E. Recomendações de adubação e calagem para o estado de São Paulo. Campinas Instituto Agronômico, 1985. 100 p., (Boletim n $\left.{ }^{\circ} .100\right)$

HAAG, H.P.; MINAMI, K. Nutrição mineral de hortaliças LXXIII. Requerimento de nutrientes pela cultura da beterraba. Anais da EscolaSuperior de Agricultura "Luiz de Queiroz”, Piracicaba, v.XLIV, p.401-408, 1987.

HEMPHILL JR., D.D.; WEBER, M.S.; JACKSON, T.L. Table beet yield and boron deficiency as influenced by lime, nitrogen, and boron. Soil Science Society America Journal, Madison, v.46, p.1190-1192, 1982.

LASKE, P. Abonamiento de las hortalizas. Hannover: Verlagsgesellschaft für Ackerbau mbH., 1962. 51 p.

MACK, H.J. Effects of nitrogen, boron and potassium on boron deficiency, leaf mineral concentrations, and yield of table beets (Beta vulgaris L.). Communications In Soil Science Plant Analysis, New York, v.20, n.3-4, p.291-303, 1989.

PEREIRA, P.R.G.; SILVA, D.H.J.; FONTES, P.C.R.; MARTINEZ, H.E.P; BARACAT-PEREIRA, M.C. Teores de nitrato, composição mineral e produção de raízes de beterraba em solo com alto nitrogênio. Horticultura Brasileira, Brasília, v.13, n.1, p.104, 1995. (resumo 226)

SHANNON, S.; BECKER, R.F.; BOURNE, M.C. The effect of nitrogen fertilization on yield, composition and quality of table beets (Beta vulgaris L.). American Society for Horticultural Science, Alexandria, v.90, p.201-208, 1967.

TRANI, P.E.; FORNASIER, J.B.; LISBÃO, R.S. Nutrição mineral e adubação da beterraba. In: FERREIRA, M.E.; CASTELLANE, P.D.; CRUZ, M.C.P. (Ed.) Nutrição e adubação de hortaliças. Piracicaba: Associação Brasileira para Pesquisa da Potassa e do Fosfato, 1993. p.429-46.

TRANI, P.E.; GROPPO, G.A.; SILVA, M.C.P.; MINAMI, K; BURKE, T.J. Diagnóstico sobre a produção de hortaliças no estado de São Paulo. Horticultura Brasileira, Brasília, v.15, n.1, p.1924, 1997a.

TRANI, P.E.; PASSOS, F.A.; TAVARES, M.; AZEVEDO FILHO, J.A. Beterraba, cenoura, nabo, rabanete e salsa. In: RAIJ, B.; CANTARELLA, H.; QUAGGIO, J.A.; FURLANI, A.M.C. Recomendações de adubação e calagem para o estado de São Paulo (Boletim técnico $N^{o}$. 100, 2.ed.ver.atual.). Campinas: Instituto Agronômico \& Fundação IAC, 1997b. p.174. 